\section{Pendred syndrome}

\author{
William Reardon, Richard C Trembath
}

Mothercare Unit of
Paediatric Genetics
and Fetal Medicine,
Institute of Child
Health,
30 Guilford Street,
London WC1N 1EH,
UK
W Reardon
Departments of
Genetics and
Medicine, University
of Leicester,
University Road,
Leicester LE2 7RT, UK
Correspondence to:
Dr Reardon.

Mothercare Unit of Paediatric Genetics and Fetal Medicine, Institute of Child 30 Guilford Street, London WC1N 1EH, UK

Departments of Medicine, University of Leicester, Dr Reardon.
Almost uniquely among syndromic forms of deafness, Pendred syndrome has been the subject of wide ranging epidemiological study indicating that it may account for up to $7.5 \%$ of all cases of childhood deafness. ${ }^{1}$ Remarkably the condition has been substantially overlooked in recent years. However, the recent mapping of the Pendred locus to chromosome 7q31 and the reporting of locus homogeneity have brought the syndrome back into focus as a distinct clinical entity. ${ }^{23}$

( $\mathcal{H}$ Med Genet 1996;33:1037-1040)

Key words: Pendred syndrome; deafness; thyroid dysfunction.

The natural history of the syndrome first described by Vaughan Pendred (fig 1) in 1896 has not followed a streamlined course, largely owing to the variable clinical presentation and the absence of a specific diagnostic test. Pendred reported an Irish family, resident in the north of England, in which two adult females

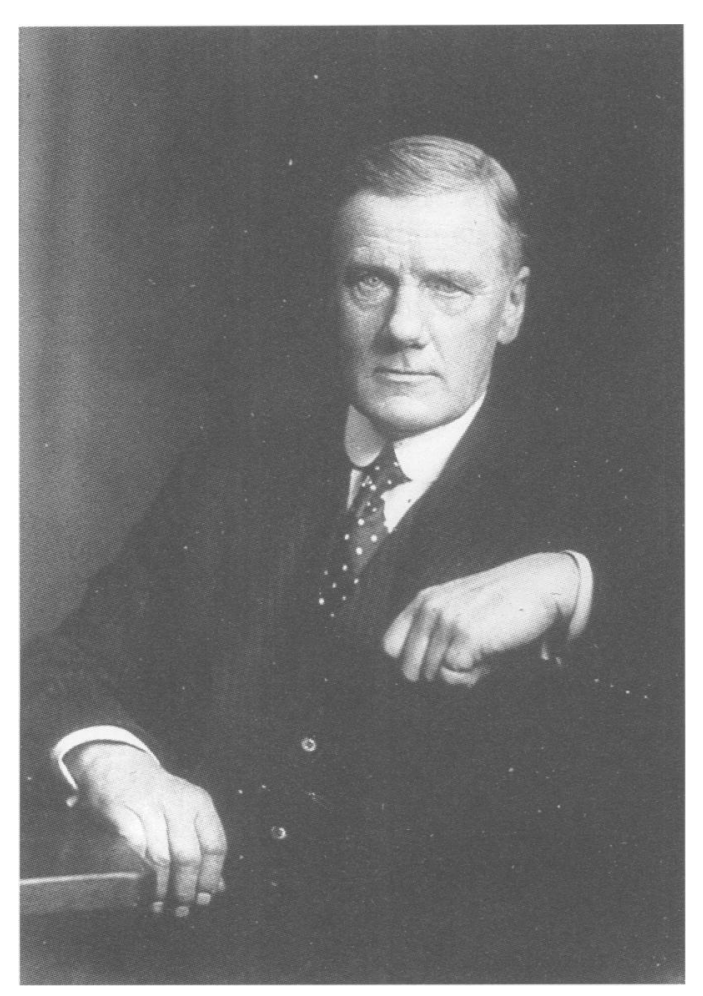

Figure 1 Dr Vaughan Pendred (1869-1945), after whom the syndrome is named. were deaf and had large goitres, the first evidence of which was dated from the age of $13 .{ }^{4}$ Over 30 years later and without reference to Pendred's report, Brain ${ }^{5}$ presented details of four families with two or more children affected. Phenotypic variability and, occasionally, difficulty in classifying families/patients as having Pendred syndrome or otherwise are central themes emerging both from Brain's report and Fraser's later study of 207 families, comprising 334 cases of Pendred syndrome. ${ }^{1}$ Fraser's study established Pendred syndrome as an important and relatively common cause of inherited deafness, estimating a prevalence of 75 cases per million population.

The exact proportion of genetic deafness attributable to Pendred syndrome is uncertain, Fraser's estimate of $7.5 \%$ of all childhood deafness considerably exceeding more recent estimates. ${ }^{6}$ The $7.5 \%$ estimate was derived from an adult deaf population, the argument being that the lower figures, varying from $4.3 \%$ to $6.4 \%$ obtained in large scale studies of paediatric deaf populations, masked those cases of Pendred syndrome in whom the goitre was not detectable in childhood. ${ }^{1}$ That this high prevalence figure has not been corroborated in later studies may, at least in part, reflect difficulties in ascertainment, there being no single definitive diagnostic test for the condition.

That deafness and thyroid dysfunction are aetiologically related is beyond dispute. Trotter $^{7}$ summarised the situation in 1960 , distinguishing clearly between deafness in relation to endemic cretinism/goitre and sporadic goitre with deafness (Pendred syndrome). He drew attention to the several reports identifying unusually high rates of deafness in geographically distinct areas noted to be regions of endemic goitre. Frequently the deafness and goitre were observed in the same people and a likely causative link was further substantiated by the observation in Switzerland of a positive correlation between the falling incidence of deafness over time and the extent of salt iodisation.

Fraser's criteria for the diagnosis were congenital deafness, goitre, and a positive perchlorate discharge test. Latterly some authors have advocated that a Mondini malformation of the cochlea be included as an essential prerequisite to the diagnosis ${ }^{8}$ and have recognised a degree of plasticity in the matter of goitre. 

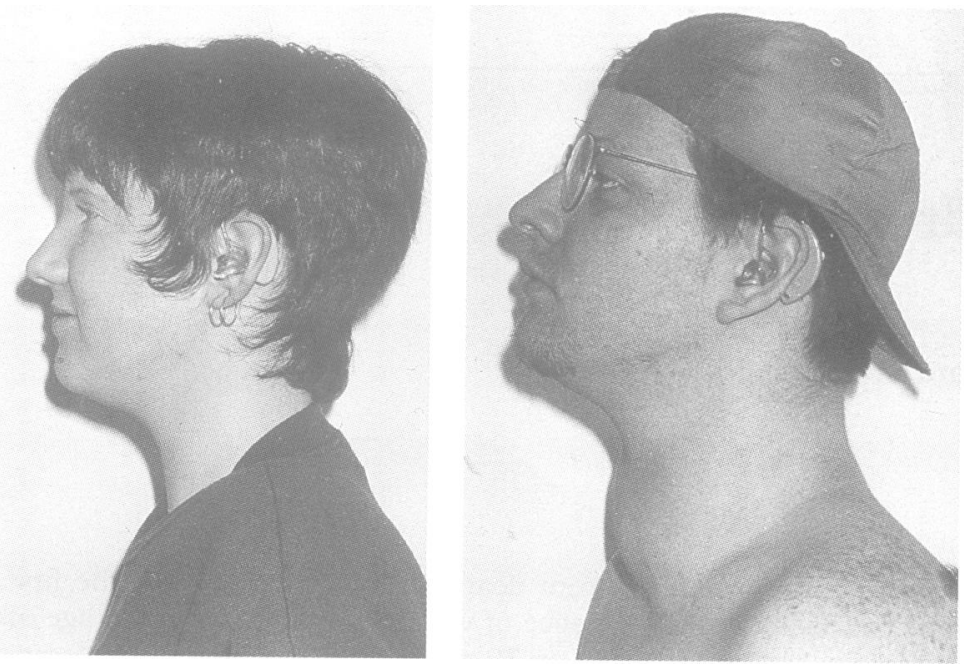

Figure 2 Brother and sister with Pendred syndrome to show the intrafamilial variability in the goitre which may be seen. Neither of these patients has had surgery.

\section{Congenital deafness: audiovestibular studies in Pendred syndrome}

Typically the disturbance is of moderate to severe degree sensorineural loss, being more pronounced in the higher frequencies. The deafness is thought to be congenital and is certainly prelingual in most cases. ${ }^{1}$ One report of 17 unrelated cases found evidence of progression of the hearing impairment in three patients ${ }^{9}$ and in our own series of 50 cases we have observed cases in whom the hearing dysfunction escaped detection until adult life. Despite anecdotal observations of abnormality, ${ }^{9-13}$ there has been no detailed systematic study of vestibular parameters in Pendred syndrome.

\section{Thyroid dysfunction in Pendred syndrome}

Classically the goitre appears in mid-childhood, but is often postpubertal, especially in males. There are rare instances of congenital goitre. The goitre tends to be diffuse initially but may become nodular. There is distinct intrafamilial variability in the presence and extent of goitre between affected subjects (fig 2). While Johnsen $e t a l^{9}$ suggest that up to $50 \%$ of cases are hypothyroid, Fraser's experience, in a far

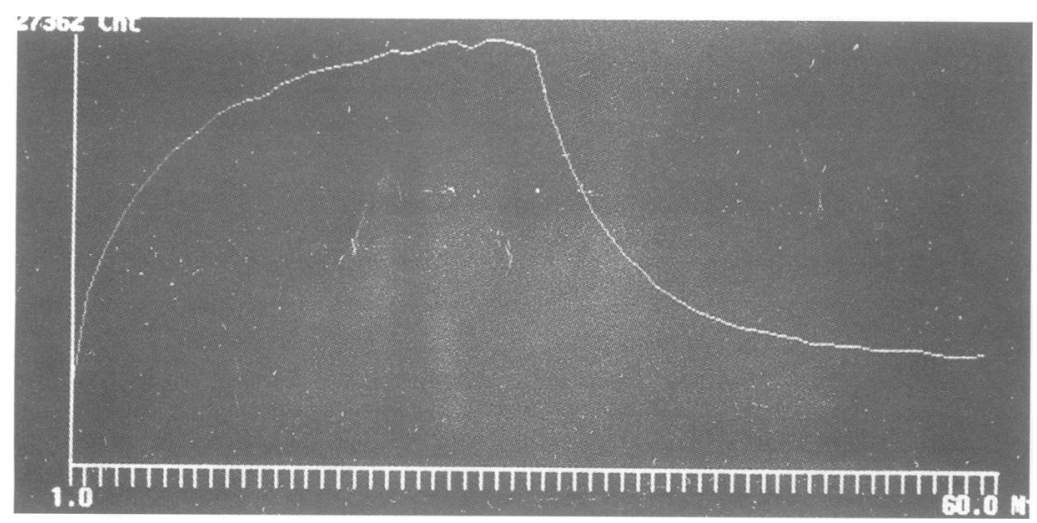

Figure 3 The abnormal perchlorate discharge test result observed in Pendred syndrome. Note the rapid discharge of iodide, as evidenced by the fall in radioactivity count, following perchlorate challenge. larger study, was that most cases are euthyroid. ${ }^{1}$ Many cases do come to surgery for tracheal compression, this hazard being more common among females. Most cases undergoing subtotal thyroidectomy suffer recurrence of the goitre. While goitre was essential to the diagnosis in early reports, identification of the thyroidal defect before the development of goitre is now facilitated by the perchlorate discharge test. $^{14}$

\section{The perchlorate discharge test}

In a normally functioning thyroid gland inorganic iodide, having been trapped, is immediately organified by binding to thyroglobulin. Iodination of thyroglobulin requires the generation of $\mathrm{H}_{2} \mathrm{O}_{2}$ and the oxidation of iodide and tyrosyl residues by the enzyme thyroid peroxidase. The subsequent coupling of iodotyrosyls into iodothyronines $T_{4}$ and $T_{3}$ within the matrix of thyroglobulin is also governed by thyroid peroxidase. ${ }^{15}$ Perchlorate and thiocyanate unmask defects of organification by provoking the discharge of inorganic iodide from the gland. As a result, administration of potassium perchlorate in the presence of an organification defect, having primed the thyroid with radioiodide results in a dramatic fall in the counting rate from sequestered radioiodide over the thyroid, as observed by Morgans and Trotter in $1958 .^{14}$ In the case of complete block of organification, thyroidal radioactivity declines in parallel with the plasma radioiodide. A discharge in response to perchlorate of $10 \%$ or greater is considered abnormal (fig 3). Similar levels of iodide discharge may also be recorded in autoimmune thyroid disease ${ }^{1617}$ and thyrotoxic patients treated with radioactive iodine. Hence the perchlorate discharge data must always be considered in the context of clinical and other investigative data.

\section{Radiological studies in Pendred syndrome}

The first radiological report appears to be that of Illum et al, ${ }^{11}$ who observed Mondini abnormalities in eight of 13 cases examined by temporal bone tomography. CT demonstration of the Mondini abnormality (fig 4) was reported by Johnsen $e t a l^{18}$ in a cohort of cases already known to have the malformation from tomograms. The Mondini malformation is neither a consistent nor specific observation in Pendred syndrome, being well recognised in other forms of deafness, both genetic and nongenetic.

The inherited basis of Pendred syndrome Brain $^{5}$ considered a single recessive trait of pleiotropic effect, segregating in a mendelian manner affecting "several children of normal parents in the absence of a family history of the complaint ... manifested by both males and females equally" as the likely basis of Pendred syndrome. Fraser ${ }^{1}$ concurred, the evidence for autosomal recessive inheritance in his study (the largest on record) being supported not 


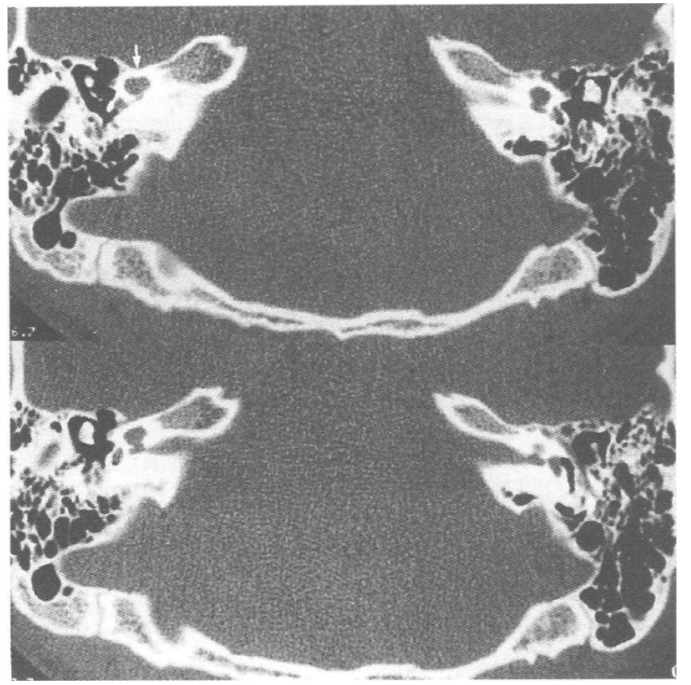

Figure 4 Axial CT section showing probable slight deficiency of the interscalar septum in the distal coils of the cochlea to give a bilateral Mondini cochlear malformation (arrowed).

only by segregation analysis but also by the observation of parental consanguinity in 22 of 186 fully documented pedigrees with Pendred syndrome. More recently, Gausden et a ${ }^{19}$ have drawn attention to several examples of definitely affected, unrelated subjects marrying and producing only affected offspring, observations which in themselves are strongly supportive of autosomal recessivity and locus homogeneity. McKusick, ${ }^{13}$ while accepting that most cases are likely to represent an autosomal recessive condition, does cite a single example of "pseudodominance". It seems clear that Pendred syndrome does comply with the criteria for autosomal recessive inheritance in most families.

\section{Molecular genetic studies in Pendred syndrome}

Subsequent to the exclusion of TPO and thyroglobulin loci, ${ }^{319}$ Pendred syndrome has recently been mapped to chromosome $7 \mathrm{q} 31$. Sheffield $e t$ $a l^{3}$ studied two inbred Middle Eastern kindreds and, applying the autozygosity mapping strategy, defined a $9 \mathrm{cM}$ critical interval of homozygosity. In a panel of 12 unrelated British and Israeli sibships, Coyle $e t a l^{2}$ independently mapped the Pendred locus to a $5 \mathrm{cM}$ region flanked by the markers D7S501 and D7S523. Neither study showed any evidence for locus heterogeneity. We have recently exploited these findings in a diagnostic capacity in a sibship, offspring of first cousin parents, presenting with deafness. Thyroid function tests were normal and neuroradiology of the cochlea was normal. However, in view of the clinical impression of slight enlargement of the thyroid in one of the sibs, we sought evidence for homozygosity at the Pendred locus (fig 5), rather than proceeding directly to perchlorate discharge testing. Homozygosity was confirmed and a perchlorate discharge of $60 \%$ was subsequently recorded in this child.

Interestingly, Pendred syndrome maps to the region containing the recently reported non-

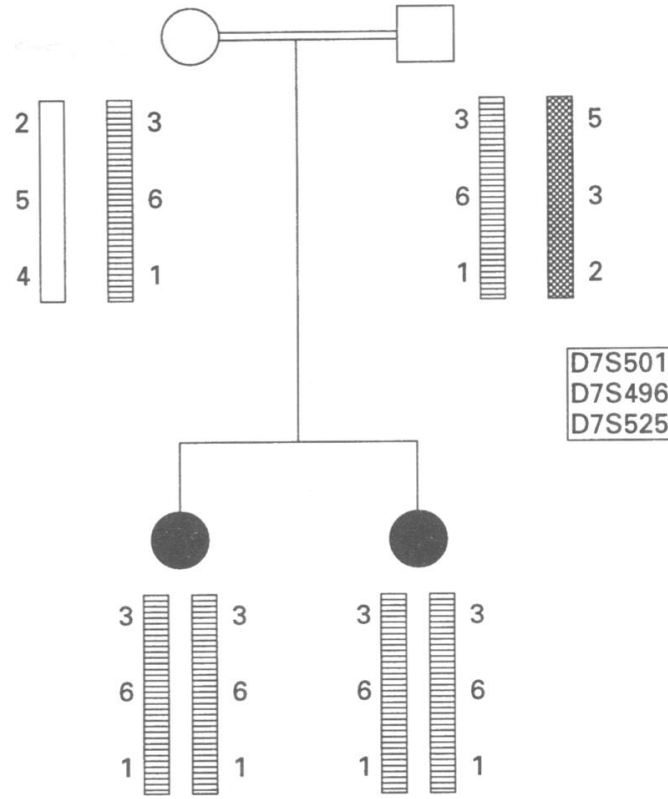

Figure 5 II. 1 and II. 2 presented with congenital profound sensorineural deafness. All investigations including thyroid function were normal. The molecular investigation confirms that they are identical by descent for the region of $7 q$ containing the Pendred locus. Perchlorate discharge test undertaken subsequently was positive, with a discharge of $60 \%$.

syndromic autosomal recessive deafness locus DFNB4. This latter report was based upon a single inbred Druze kindred in Israel ${ }^{20}$ in which the disorder was localised by the autozygosity approach. In the context of the apparent colocalisation of Pendred syndrome and DFNB4, it is worth noting that the Druze family was not investigated for Pendred syndrome. Whether DNFB4 represents Pendred syndrome, an adjacent deafness locus, or an allelic form remains to be resolved. The identification of non-syndromic autosomal recessive loci for deafness is complicated by significant locus heterogeneity, nine such loci having been mapped to date. In contrast, the locus homogeneity found in Pendred syndrome and the availability of multiple independent families should facilitate a positional cloning approach to gene identification.

\section{Towards the molecular basis of Pendred syndrome}

The linkage interval for Pendred syndrome does not contain any recognised candidate genes. Foremost among the prerequisites of any such candidate are the reconciling of both thyroid and cochlear involvement. Both organs are of ectodermal derivation. Moreover, thyroid hormone receptor genes are widely expressed during auditory neurogenesis ${ }^{21}$ and homozygous deletion for the thyroid hormone beta receptor is known to result in sensorineural deafness. ${ }^{223}$ Little is known of the role or contribution of iodide to normal inner ear development and function. The pathway of iodide organification required in the production of thyroid hormones occurs within the follicular cells of the thyroid gland. This process requires 
the generation of $\mathrm{H}_{2} \mathrm{O}_{2}$ in conjunction with the enzyme thyroid peroxidase. In the total iodide organification defect (TIOD), an independent autosomal recessive condition characterised by congenital hypothyroidism alone, and a greater than $90 \%$ iodide discharge following perchlorate administration, a range of mutations in the coding sequence of the thyroid peroxidase gene have been established. ${ }^{24-26}$ For two distinct reasons the molecular basis of Pendred syndrome is likely to represent an organification defect. Firstly, the perchlorate induced discharge of iodide in TIOD shows a causal relationship between defective organification and perchlorate sensitivity. Secondly, Sheffield et $a l,{ }^{3}$ by in vitro analysis of thyroid tissue from affected patients, have shown a post iodide uptake defect and an organification defect with proportionate reduction in $\mathrm{T}_{3}$ secretion. Neither of these observations exclude a defect in the intracytoplasmic domains of the iodide transporter.

Our work on Pendred syndrome is supported by the MRC and the Hearing Research Trust. We are grateful to our collaborators Dr Peter Phelps and Professor Keith Britton for permission to reproduce radiographs and perchlorate discharge results, to reproduce radiographs and perchlorate discharge results,
respectively. Fig 5 is reproduced courtesy of Ms E Gausden. We respectively. Fig 5 is reproduced courtesy of Ms E Gausden. We
acknowledge the assistance of the Royal College of Physicians in acknowledge the assistance of the Royal College of Physicians in
locating fig 1 . We especially thank Becky Coffey for reading the locating fig

1 Fraser GR. Association of congenital deafness with goitre (Pendred's syndrome). Ann Hum Genet 1965;28:201-48. (Pendred's syndrome). Ann Hum Genet 1965;28:201-48.
Coyle B, Coffey R, Armour JAL, et al. Pendred syndrome (goitre and sensorineural hearing loss) maps to the region containing the nonsyndromic deafness gene DFNB4 on chromosome 7. Nat Genet 1996;12:421-3.

3 Sheffield VC, Kraiem Z, Beck JC, et al. Pendred syndrome maps to chromosome 7q21-34 and is caused by an intrinsic defect in thyroid iodine organification. Nat Genet 1996; 12:424-6.

4 Pendred V. Deaf mutism and goitre. Lancet 1896;ii:532.

5 Brain WR. Heredity in simple goitre. $Q \mathcal{F}$ Med 1927;20: 303-19.

6 Coakley JC, Keir EH, Connelly JF. The association of thyroid dyshormonogenesis and deafness (Pendred syndrome): experience of the Victorian neonatal thyroid drome): experience of the Victorian neonatal thyroid 398-401.

7 Trotter WR. The association of deafness with thyroid dysfunction. Br Med Bull 1960;16:92-8.
8 Johnsen T, Sorensen MS, Feldt-Rasmussen U, et al. The variable intrafamiliar expressivity in Pendred's syndrome. Clin Otolaryngol 1989;14:395-9.

9 Johnsen T, Larsen C, Friis J, et al. Pendred's syndrome. Acoustic, vestibular and radiological findings in 17 un related patients. f Laryngol Otol 1987;101:1187-92.

10 Arnvig J. Vestibular function in deafness and severe hardnes of hearing. Acta Otolaryngol (Stockh) 1955;45:283-8.

11 Illum P, Kiaer HW, Hvidberg-Hansen J, et al. Fifteen cases of Pendred's syndrome. Arch Otolaryngol 1972;96:297-304

12 Das VK. Pendred's syndrome with episodic vertigo, tinnitus and vomiting and normal bithermal caloric responses. $\mathcal{F}$ Laryngol Otol 1987;101:721-2.

13 McKusick VA. Mendelian inheritance in man. 11 th ed. Baltimore: Johns Hopkins University Press, 1994

14 Morgans ME, Trotter WR. Association of congenital deaf ness with goitre. The nature of the thyroid defect. Lancet 1958;i:607-9.

15 Vassart G, Dumot JE, Refetoff S. Thyroid disorders. In: Scriver CR, Beaudet AL. Sly WS, Valle D, eds. The inherited basis of metabolic disease. 7th ed. New York: McGraw-Hill, 1995:2883-928.

16 Morgans ME, Trotter WR. Defective organic binding of odide by the thyroid in Hashimoto's thyroiditis. Lance 1957;i:553-5.

17 O'Mahoney CF, Luxon LM, Chew SL, et al. When the triad of congenital hearing loss, goitre and perchlorate positive is not Pendred's syndrome. 7 Audiol Med (in press).

18 Johnsen T, Videbaek H, Olsen KP. CT-scanning of the cochlea in Pendred's syndrome. Clin Otolaryngol 1989;14: 389-93.

19 Gausden E, Armour JAL, Coyle B, et al. Thyroid peroxidase evidence for disease gene exclusion in Pendred syndrome. evidence for disease gene exclus

20 Baldwin CT, Weiss S, Farrer LA, et al. Linkage of congenital recessive deafness (DFNB4) to chromosome $7 \mathrm{q} 31$ and evidence for genetic heterogeneity in Middle Eastern Druze population. Hum Mol Genet 1995;4:1637-42.

21 Bradley DJ, Towle HC, Young WS III. Alpha and beta thyroid hormone receptor (TR) gene expression during auditory neurogenesis: evidence for TR isoform-specific transcriptional regulation in vivo. Proc Natl Acad Sci USA 1994;91:439-43.

22 Takeda K, Balzano S, Sakurai A, DeGroot LJ, Refetoff $S$. Screening of 19 unrelated families with generalised S. Screening of 19 unrelated families wit in the thyroid horm in the thyroid hormone receptor beta gene and the de-

23 Takeda K, Sakurai A, DeGroot LJ, Refetoff S. Recessive inheritance of thyroid hormone resistance caused by complete deletion of the protein coding region of the thyroid hormone receptor beta gene. $\mathcal{F}$ Clin Endocrinol Metab 1992 74:49-55.

24 Abramowicz MJ, Targovnik HM, Varela V, et al. Identification of a mutation in the coding sequence of the human thyroid peroxidase gene causing congenital goiter. 7 Clin Invest 1992;90:1200-4.

25 Bikker H, Denhartog MT, Baas F, et al. 20-base pair duplication in the human thyroid peroxidase gene results in a total iodide organification defect and congenital hypothyroidism. f Clin Endocrinol Metab 1994;79:248-52

26 Bikker H, Vulsma $\mathrm{T}$, Baas $\mathrm{F}$, et al. Identification of 5 nove inactivating mutations in the human thyroid peroxidase gene by denaturing gradient gel-electrophoresis. Hum Mutat 1995;6:9-16. 